\title{
Influence of Different Palladium Precursors on the Properties of Solution-Combustion-Synthesized Palladium/ Ceria Catalysts for Methane Combustion
}

\author{
Sara Colussi,${ }^{*[a]}$ Arup Gayen,${ }^{[b]}$ Marta Boaro, ${ }^{[a]} J o r d i$ Llorca ${ }^{[c]}$ and Alessandro Trovarelli ${ }^{[a]}$
}

A series of $\mathrm{Pd} / \mathrm{CeO}_{2}$ catalysts was prepared by solution combustion synthesis (SCS) using different Pd precursors. The powders were characterized by complementary techniques such as BET surface area measurements, X-Ray diffraction analysis, XRay photoelectron spectroscopy, temperature-programmed reduction, temperature-programmed oxidation, and high-resolution TEM. The results obtained evidenced the formation of a Pd-Ce solid solution on all SCS samples. This solid solution is in the form of an ordered supercell structure only in the SCS catalyst prepared from palladium nitrate. This was correlated to the heat of reaction between $\operatorname{Pd}\left(\mathrm{NO}_{3}\right)_{2}$ and the fuel. The samples were tested for methane catalytic combustion, and the reaction rates on all SCS samples were approximately twice that of the impregnated counterpart, irrespective of the precursor. This was attributed to the presence of the Pd-O-Ce solid solution, which gave rise to strong $\mathrm{Pd}$-ceria interactions.

\section{Introduction}

Solution combustion synthesis (SCS) is an attractive method for the preparation of extremely dispersed catalyst nanopowders in a single, cost-effective step. ${ }^{[1]}$ This technique is based on the direct reaction of catalyst precursors (oxidizers) with a fuel (reducing agent). All reactants are dissolved in water, and the solution is heated in a furnace in which the combustion takes place with the formation of a solid product. The general scheme for the SCS of a metal oxide using oxalyl dihydrazide $\left(\mathrm{ODH}, \mathrm{C}_{2} \mathrm{H}_{6} \mathrm{~N}_{4} \mathrm{O}_{2}\right)$ as a fuel is shown in Equation (1): ${ }^{[2]}$

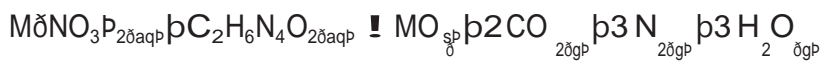

The powders obtained by this method show interesting properties, such as small particle size and fine dispersion, because of the evolution of gases during reaction that can destroy larger agglomerates and lead to the formation of smaller

[a] Dr. S. Colussi, Prof. M. Boaro, Prof. A. Trovarell

Department of Chemistry, Physics and Environment

University of Udine

Via del Cotonificio 108, IT-33100 Udine (Italy)

E-mail : sara.colussi@uniud.it

[b] Dr. A. Gayen

DepartmentofChemistry

Jadavpur University

Kolkata 700032 (India)

[c] Prof. J. Llorca

Insitut de Tecniques Energetiques

and Centre for Research in Nanoengineering

Universitat Politecnica de Catalunya, 08028 Barcelona (Spain) nanoparticles compared to conventional methods. There are several examples that demonstrate how, with this technique, it is possible to prepare structured catalysts (i.e., monoliths) by loading the catalyst powder directly onto the surface of the ceramic or metal support. ${ }^{[3]}$ Moreover, some patents describe the possibility of the industrial scale-up of this synthesis approach. ${ }^{[4]}$ As a result of the intriguing characteristics of the powders and the simple preparation method, many efforts have been devoted to study the performances of SCS materials for different applications, which range from three-way catalysts for automotive exhausts aftertreatment ${ }^{[3 a, 5]}$ to composite mate-

rials for ion batteries, ${ }^{[6]}$ ceramic powders for solid oxide fuel cells ${ }^{[7]}$ metal-based catalysts for reforming reactions, ${ }^{[8]}$ luminescent materials, ${ }^{[9]}$ biomaterials for medicine use ${ }^{[10]}$ and catalysts for oxidation reactions. ${ }^{[11]}$ Within the last topic, we investigated the performances of $\mathrm{Pd} / \mathrm{CeO}_{2}$ catalysts for methane combustion prepared by SCS and compared their catalytic activity with that of the corresponding impregnated samples. ${ }^{[12]} \mathrm{We}$ observed a significant increase in methane combustion rates on SCS samples with respect to the impregnated ones. SCS samples presented a peculiar $\mathrm{Pd}-\mathrm{O}-\mathrm{Ce}$ supercell structure in which alternate $\mathrm{Ce}$ atoms were substituted by $\mathrm{Pd}$ atoms, which led to the formation of ordered arrays of oxygen vacancies together with highly undercoordinated $O$ atoms. DFT calculations performed by Mayernick and Janik ${ }^{[13]}$ proved theoretically that this superstructure is extremely active for methane combustion, in agreement with our experimental results. Other authors indicated that the incorporation of metal ions into an oxide lattice, which implies the formation of oxide ion vacancies, is responsible for the higher catalytic activity in combustion reactions that typically involve oxygen and fuel dissociation on the catalyst surface. ${ }^{[11 b]}$

SCS samples present other characteristics that could be involved in the higher activities recorded for these catalysts. For 
example Specchia et al. reported the presence of dispersed $\mathrm{Pd}^{2+}$ ions together with $\mathrm{Pd}$ and $\mathrm{PdO}$ on Pd-ceria-zirconia samples prepared by SCS and attributed the high activity observed to a synergistic effect between the different Pd species. ${ }^{[11 a]} \mathrm{We}$ have reported a similar situation for the catalytic combustion of propane and dimethyl ether on $\mathrm{Pd} / \mathrm{CeO}_{2}$ catalysts, in which the coexistence of highly active $\mathrm{Pd}^{\prime \prime}$ centers with $\mathrm{Pd}$ and $\mathrm{PdO}$ species was considered to be responsible for the higher reaction rates of SCS samples with respect to impregnated ones. ${ }^{[14]}$

To obtain the desired properties and maximize the potential of SCS catalysts, one should be able to finely tune the synthesis procedure. From a practical point of view, SCS is a very simple technique and the theoretical background is clear; nevertheless, the influence of individual parameters (i.e., role of fuel, precursors, combustion temperature, etc.) on the synthesized materials are complex to study because of the high exothermicity of the reaction and its fast evolution. Recently, some studies have focused on the role of the fuel-to-oxidizer ratio and on reaction thermodynamics modeling, ${ }^{[10 b, 15]}$ but many aspects still need to be investigated in depth. In this work, we try to address this issue by characterizing SCS $\mathrm{Pd} / \mathrm{CeO}_{2}$ samples prepared from different $\mathrm{Pd}$ precursors to evaluate the effect of this parameter on the formation of the supercell structure. Moreover, we study the catalytic behavior of the materials for the combustion of methane by reaction rate measurements performed in a recycle reactor, with the aim to give more insights into their peculiar catalytic activity.

\section{Results and Discussion}

The Pd precursor, Pd loading, and surface area of the samples considered in this work are reported in Table 1. The measured $\mathrm{Pd}$ amount is close to the nominal loading of $2 \mathrm{wt} \%$, and the loading on SCS2-AC is slightly lower than that of the other samples. In the following, all the quantitative results will be calculated on a per gram of $\mathrm{Pd}$ basis. In general all catalysts present low surface areas, irrespective of the preparation method and the $\mathrm{Pd}$ precursor. The addition of $\mathrm{Pd}$ salt during SCS, even if in very low amount, decreases the surface area of the catalysts significantly, as evidenced by comparing $\mathrm{Pd} / \mathrm{CeO}_{2}$ with the $\mathrm{CeO}_{2}$ support prepared by the solution combustion of ceric ammonium nitrate with $\mathrm{ODH}$.

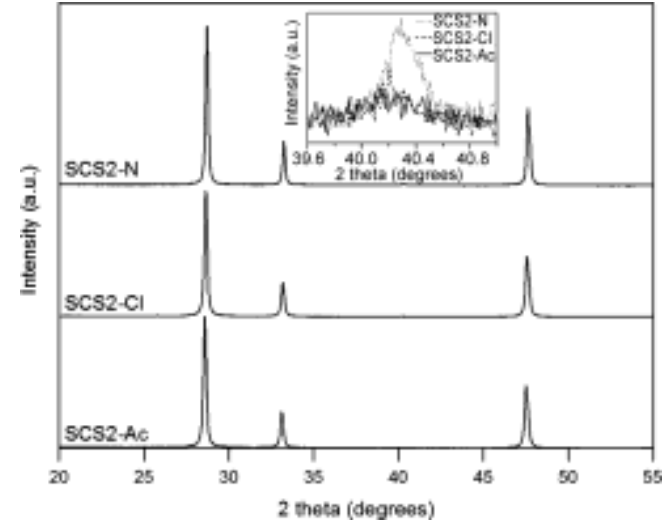

Figure 1. XRD profiles of the SCS samples. Inset: Pd metal peak $(2 q=40.28)$.

XRD profiles of the SCS samples are shown in Figure 1. The XRD patterns of the ceria supports are almost identical for all samples, whereas a difference can be observed for the $\mathrm{Pd}$ metal peaks $(2 q=40.28)$. The presence of Pd metal on SCS2-N can be seen clearly in the inset of Figure 1, and the Pd metal peak has a lower intensity for SCS2-Cl and SCS2-Ac. No peaks from palladium oxide $(2 \mathrm{q}=33.98)$ can be distinguished on any of the SCS samples. The mean crystal size of ceria calculated by the Scherrer equation is between 30 and $45 \mathrm{~nm}$ for all catalysts. On the sample prepared by incipient wetness impregnation (IWI; Figure S1) no Pd metal is detected, but small PdO peaks at $2 q=33.9$ and 42.38 are observed. The calculated crystal size of ceria in the IWI catalyst is $16 \mathrm{~nm}$.

Rietveld analysis of the SCS catalysts indicates that the structural features are compatible with the presence of a solid solution in which Pd partially enters the ceria lattice (Table 1). The amount of $\mathrm{Pd}$ in solid solution, calculated according to Vegard's law, varies slightly with the Pd precursor. The formation of a $\mathrm{Ce}_{1-x} \mathrm{Pd}_{\mathrm{x}} \mathrm{O}_{2-\mathrm{d}}$ solid solution on 1 at $\% \mathrm{Pd} / \mathrm{CeO}_{2}$ samples prepared by SCS starting from a $\mathrm{PdCl}_{2}$ precursor was reported by Priolkar and co-workers. ${ }^{[16]}$ According to their work, this solid solution comprises $\mathrm{Pd}^{2+}$ ions stabilized in $\mathrm{Ce}^{4+}$ sites. For the IWI sample, the variation in the lattice parameter is too small to assume the inclusion of $\mathrm{Pd}$ into the ceria lattice.

The X-ray photoelectron spectroscopy (XPS) results of the as-prepared and spent catalysts are summarized in Table 2 (see Figure S7 of the Supporting Information for XPS spectra). By using XPS, it has been possible to identify different $\mathrm{Pd}$ species that have been ascribed to $\mathrm{Pd}^{0}$ metal (binding energy $(B E)=$ $335.6 \mathrm{eV}), \mathrm{Pd}^{\mathrm{II}}$ species (BE= $337.6 \mathrm{eV})$, and nonstoichiometric palladium oxide with an intermediate oxidation state $(\mathrm{BE}=$ $336.5 \mathrm{eV}) .{ }^{[17]}$ It can be observed that, in agreement with the XPS spectra of fresh samples, $\mathrm{Pd}$ metal is detected only on the SCS samples, whereas IWI shows the presence of oxidized Pd spe- [a] As measured by inductively coupled plasma atomic emission spectroscopy (ICP-AES). [b] Calculated according to Vegard's law and assuming a $\mathrm{Ce}^{4+}$ ionic radius of $0.97 \mathrm{C}$ and a $\mathrm{Pd}^{2+}$ ionic radius of $0.86 \mathrm{C}$. $\mathrm{R}_{\mathrm{wp}}=$ weighted profile $R$ factor. $R_{F}{ }^{2}=$ structure $R$ factor. $c^{2}=\left(R\right.$ wo $R$ exp $p^{2}$, where $R$ expis the expected $R$ factor

\begin{tabular}{|c|c|c|c|c|c|c|c|c|}
\hline Sample & Pd precursor & $\begin{array}{l}\text { Pd loading } \\
\text { [wt\% }^{[\mathrm{aa}]}\end{array}$ & $\begin{array}{l}\text { Surface area } \\
{\left[\mathrm{m}^{2} \mathrm{~g}^{-1}\right]}\end{array}$ & $\begin{array}{l}\mathrm{R}_{\mathrm{wp}} \\
{[\%]}\end{array}$ & $\mathrm{R}_{\mathrm{F}}{ }^{2}$ & $c^{2}$ & Cell parameter & Composition $^{[b]}$ \\
\hline IWI & $\mathrm{Pd}\left(\mathrm{NO}_{3}\right)_{2}$ & 1.74 & 12.2 & 6.8 & 4.7 & 2.41 & $5.4110(1)$ & - \\
\hline SCS2-N & $\mathrm{Pd}\left(\mathrm{NO}_{3}\right)_{2}$ & 1.85 & 6.3 & 7.7 & 4.8 & 1.69 & $5.4103(1)$ & $\mathrm{Ce}_{0.97} \mathrm{Pd}_{0.03} \mathrm{O}_{2-\mathrm{d}}$ \\
\hline SCS2-Cl & $\mathrm{PdCl}_{2}$ & 1.84 & 5.7 & 6.4 & 4.9 & 1.16 & $5.4108(1)$ & $\mathrm{Ce}_{0.99} \mathrm{Pd}_{0.01} \mathrm{O}_{2-\mathrm{d}}$ \\
\hline SCS2-Ac & $\mathrm{Pd}\left(\mathrm{O}_{2} \mathrm{CCH}_{3}\right)_{2}$ & 1.41 & 8.9 & 6.2 & 4.5 & 1.23 & $5.4105(1)$ & $\mathrm{Ce}_{0.98} \mathrm{Pd}_{0.02} \mathrm{O}_{2-\mathrm{d}}$ \\
\hline $\mathrm{CeO}_{2} \mathrm{SCS}$ & - & - & 16.2 & 6.9 & 7.1 & 3.10 & $5.4113(1)$ & - \\
\hline
\end{tabular}




\begin{tabular}{|c|c|c|c|c|}
\hline Sample & $\begin{array}{l}\text { atomic ratio } \\
\mathrm{Pd} / \mathrm{Ce}\end{array}$ & $\begin{array}{l}\mathrm{Pd}^{0} \\
{[\%]}\end{array}$ & $\begin{array}{l}\mathrm{PdO}_{x} \\
{[\%]}\end{array}$ & $\begin{array}{l}\mathrm{Pd}^{\prime \prime} \\
{[\%]}\end{array}$ \\
\hline IWI & 0.078 & 0 & 22.6 & 77.4 \\
\hline SCS2-N & 0.053 & 10.6 & 81.1 & 8.3 \\
\hline SCS2-Cl & 0.107 & 20.9 & 79.1 & 0 \\
\hline SCS2-Ac & 0.046 & 24.7 & 66.5 & 8.8 \\
\hline$|W|^{[a]}$ & 0.063 & - & 13.7 & 86.3 \\
\hline SCS2-N $\mathrm{N}^{[\mathrm{a}]}$ & 0.067 & - & 19.6 & 80.4 \\
\hline SCS2-Cl[a] & 0.067 & - & 28.5 & 71.5 \\
\hline $\operatorname{SCS} 2-\mathrm{Ac}^{[\mathrm{a}]}$ & 0.058 & - & 17.0 & 82.9 \\
\hline
\end{tabular}

cies only. Nonstoichiometric $\mathrm{PdO}_{\mathrm{x}}$ species are present in a considerably lower amount compared to that on the SCS catalysts, which indicates that bulk $\mathrm{PdO}$ is the predominant phase on the impregnated sample. However, the catalysts prepared by SCS comprise mainly $\mathrm{PdO}_{x}$, and the amount of $\mathrm{Pd}$ metal decreases in the order SCS2-Ac>SCS2-Cl>SCS2-N. PdO is equally present on SCS2-N and SCS2-Ac and absent on SCS2-Cl. The amount of nonstoichiometric $\mathrm{Pd}$ oxide shows an inverse trend with respect to the $\mathrm{Pd}$ metal content $(\mathrm{SCS} 2-\mathrm{N}>\mathrm{SCS} 2-\mathrm{Cl}>$ SCS2-Ac). The use of different $\mathrm{Pd}$ precursors has an influence on the distribution of $\mathrm{Pd}$ species in the fresh samples, and from XPS results it is clear that SCS leads to the formation of less oxidized catalysts.

A different picture is revealed if we look at the spectra of the used catalysts, collected after one heating/cooling cycle for methane combustion. The Pd metal has disappeared, and oxidized Pd" species dominate the surface composition. This is evident particularly for SCS catalysts, but it is true also for IWI, which remains slightly richer in $\mathrm{PdO}$ with respect to SCS samples.

High-resolution transmission electron microscopy (HRTEM) images of the SCS samples are shown in Figures 2-4. In general, all catalysts show well-defined ceria crystallites with particle sizes between 20 and $50 \mathrm{~nm}$, in good agreement with XRD data. The sample prepared from palladium nitrate (SCS2-N) reveals the presence of the supercell structure identified in our previous work. ${ }^{[12]}$ A characteristic image of this catalyst is shown in Figure 2. In the Fourier transform (FT) image, crystallographic spacings at 2.71 and $3.13 \mathrm{C}$ are recorded, which correspond to the $(200)$ and (111) crystallographic planes of $\mathrm{CeO}_{2}$. In the other part of the crystal (Figure 2, right), lattice fringes at $5.7 \mathrm{C}$ correspond to the forbidden $\{100\}$ diffraction, which becomes visible in the ordered $(2 \times 1)(110)$ superstructure in which one $\mathrm{Pd}$ atom substitutes one $\mathrm{Ce}$ atom every two in the crystal structure. ${ }^{[12]}$

HRTEM images of SCS2-Cl and SCS-Ac are shown in Figures 3 and 4 , respectively. Both these samples show no evidence of the formation of the ordered supercell structure. For SCS2-Cl, only $\mathrm{CeO}_{2}$ crystallites are identified and no (222) lattice fringes that are attributed to the $\mathrm{Pd}-\mathrm{O}-\mathrm{Ce}$ superstructure are observed in the HRTEM image. The analysis of SCS2-Ac reveals that this sample is constituted by well-defined $\mathrm{CeO}_{2}$ crystallites. A high-

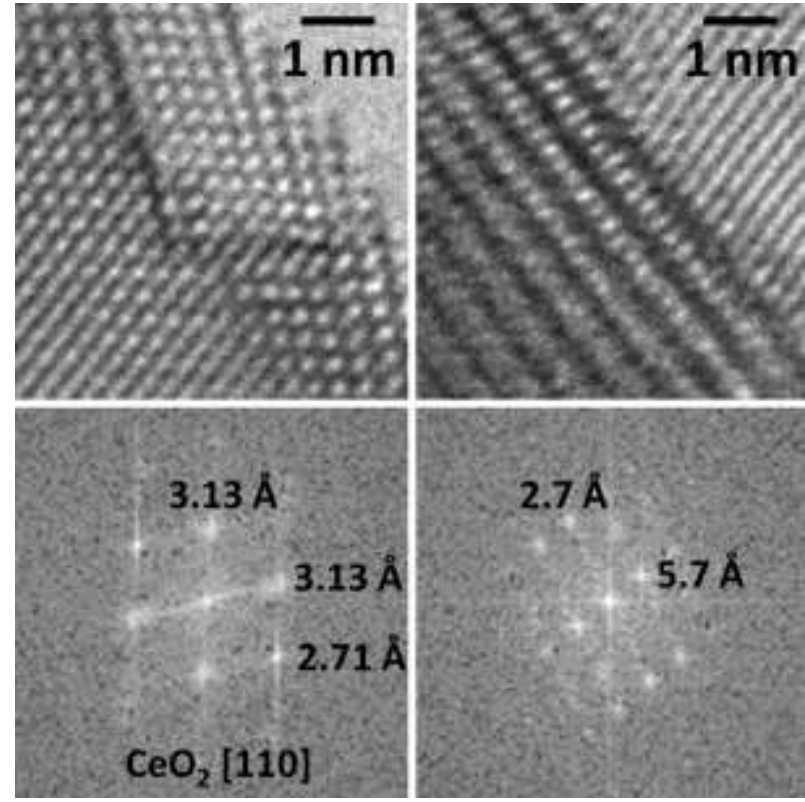

Figure 2. HRTEM images of SCS2-N (top) and their associated FT patterns (bottom).

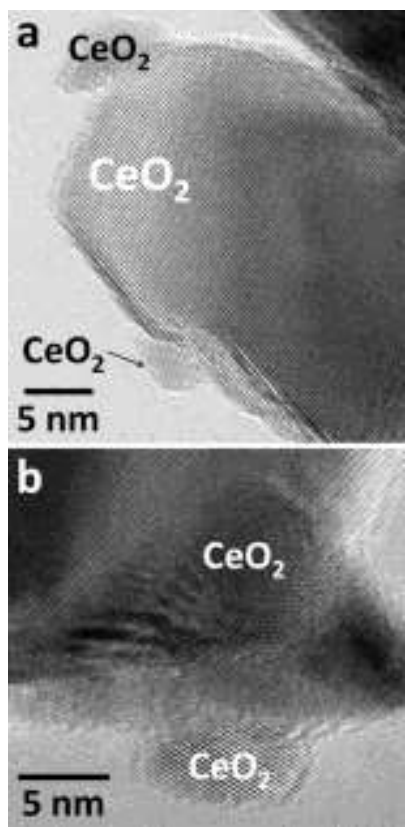

Figure 3. HRTEM images of SCS2-Cl. a and b correspond to different particles of the sample.

magnification HRTEM image that shows the presence of the (111) crystallographic planes of $\mathrm{CeO}_{2}$ is shown in Figure $4 \mathrm{~b}$. In addition to $\mathrm{CeO}_{2}$ crystallites, electron-dense particles are also identified in the image shown in Figure $4 \mathrm{a}$. These are too small ( $1 \mathrm{~nm}$ in diameter) for an accurate lattice fringe analysis, but their electron-dense nature suggests that they correspond to metallic Pd. The results of XPS (Table 2) and XRD, in which a small peak at $2 q=40.28$ is observed (inset of Figure 1a), support this identification. From the HRTEM analysis, it 


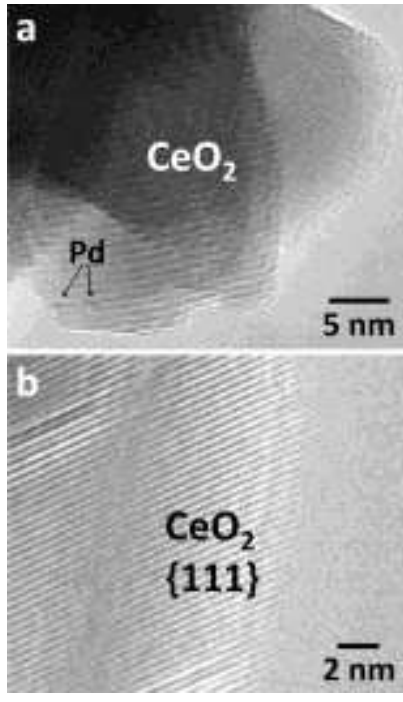

Figure 4. HRTEM images of SCS2-Ac. a and b correspond to different particles of the sample.

is possible to conclude that the ordered supercell structure described in our previous work ${ }^{[12]}$ is present only on SCS2-N, which suggests the role of the Pd precursor in the formation of this particular structure. For the other samples, the substitution of $\mathrm{Pd}^{2+}$ ions into the ceria lattice, as inferred from XRD, is not observed by HRTEM possibly because it is not ordered and/or it is limited to a very thin layer. This supercell structure can be obtained only by the dissolution of $\mathrm{Pd}^{2+}$ species with the ordering of the oxygen vacancies; the presence of a $\mathrm{Pd}$ $\mathrm{Ce}-\mathrm{O}$ solid solution does not necessarily imply the formation of a superstructure.

The HRTEM image of IWI does not reveal any particular features of this sample. Spots at $2.1 \mathrm{C}$ in the FT image correspond to (110) planes of $\mathrm{PdO}$, which indicates that $\mathrm{Pd}$ is present in the form of PdO, in agreement with XPS and XRD findings. The palladium oxide particle size on IWI is between 5 and $10 \mathrm{~nm}$ (Figure S2).

We investigated the spent SCS2-N catalyst, that is, the sample after one methane combustion cycle, by HRTEM. A lattice fringe image recorded at a magnification of $10^{6}$ is shown in Figure 5. The presence of a supercell structure is evident because there are spots not permitted in $\mathrm{CeO}_{2}$. This supercell structure is again generated by the partial substitution of $\mathrm{Ce}^{4+}$

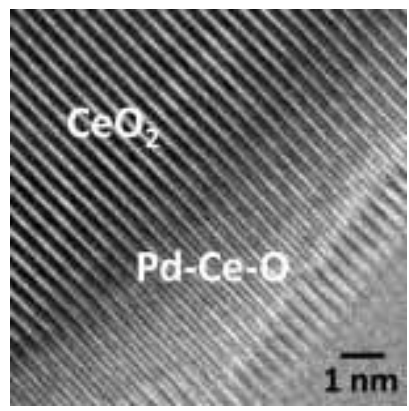

Figure 5. HRTEM image of spent SCS2-N. by $\mathrm{Pd}^{2+}$ in $\mathrm{CeO}_{2}$ with the concomitant creation of ordered oxygen vacancies.

To investigate the role of the $\mathrm{Pd}$ precursor on the properties of the catalysts prepared by SCS, we studied the effect of the different salts on the enthalpy of reaction $\mathrm{DH}_{\text {react }}$ for each SCS sample, and the results are presented in Table 3. The calcula-

Table 3. $\mathrm{DH}_{\text {react }}$ calculated for the synthesis of each SCS sample.
\begin{tabular}{|lllc|}
\hline Sample & $\mathrm{Pd}$ precursor & \multicolumn{3}{|c|}{$\mathrm{DH}_{\text {react }}\left[\mathrm{kcalmol}{ }^{-1}\right]$} \\
& & $\mathrm{Pd}_{\text {salt }}+\mathrm{CAN}+\mathrm{ODH}$ & $\mathrm{Pd}_{\text {salt }}+\mathrm{ODH}$ \\
\hline $\mathrm{SCS2}-\mathrm{N}$ & $\mathrm{Pd}\left(\mathrm{NO}_{3}\right)_{2}$ & -748 & -291 \\
$\mathrm{SCS} 2-\mathrm{Cl}$ & $\mathrm{PdCl}$ & -737 & 4 \\
SCS2-AC & $\mathrm{Pd}\left(\mathrm{O}_{2} \mathrm{CCH}_{3}\right)_{2}$ & -740 & -85 \\
\hline
\end{tabular}

tion of $\mathrm{DH}_{\text {react }}$ was performed for both the global combustion reaction [according to Equations (2)-(4) in the Experimental Section] and the reaction of the Pd salt with $\mathrm{ODH}$ alone. This latter situation can occur if some $\mathrm{Pd}$ salt is not dissolved completely or in the immediate surroundings of $\mathrm{Pd}$ salt molecules that react directly with the fuel. It can be observed that the reaction performed with the nitrate precursor has a higher $\mathrm{DH}_{\text {react }}$ (absolute value), and the difference is more evident if we exclude the contribution of ceric ammonium nitrate. The higher exothermicity observed for the palladium nitrate precursor might play a role in the formation of the ordered supercell structure observed only for the SCS2-N sample. In general, the thermodynamic properties of a solid solution change according to the mutual position of the atoms, ${ }^{[18]}$ so it is reasonable to assume that different enthalpies of reaction can result in the different ordering of $\mathrm{Pd}, \mathrm{O}$, and $\mathrm{Ce}$ atoms.

Temperature-programmed reduction (TPR) and temperatureprogrammed oxidation (TPO) were performed to investigate the redox behavior of the catalysts. The TPR profiles of the IWI and SCS catalysts are shown in Figure $6 a$ and $b$, respectively. Generally, all samples show three hydrogen-uptake regions: a low-temperature (LT) region between 233 and $423 \mathrm{~K}$, a medium-temperature (MT) region between 573 and $873 \mathrm{~K}$, and a high-temperature $(\mathrm{HT})$ region above $923 \mathrm{~K}$. From a qualitative point of view, the TPR profiles of SCS and IWI catalysts are clearly different in the LT region. Interestingly, IWI presents a single, sharp peak for hydrogen uptake, whereas the SCS samples show a complex profile that includes a combination of hydrogen-uptake and -release peaks in a wide temperature range. The difference between SCS catalysts and IWI suggests that on the impregnated sample $\mathrm{Pd}$ is present in a more homogeneous form than that on the SCS ones; this effect might be related to different particle size distribution and/or to the presence of different $\mathrm{PdO}_{x}$ species, according to that detected by XPS analysis.

The peaks in the $\mathrm{LT}$ region can be attributed to the reduction of Pd-related species as reported widely in the literature ${ }^{[19]}$ whereas the peaks in the MT and HT regions can be attributed to the reduction of surface and bulk ceria species, respectively. ${ }^{[20]}$ On the SCS samples, $\mathrm{H}_{2}$ uptake starts $\partial 50 \mathrm{~K}$ lower than that on IWI, which indicates that the SCS catalysts 

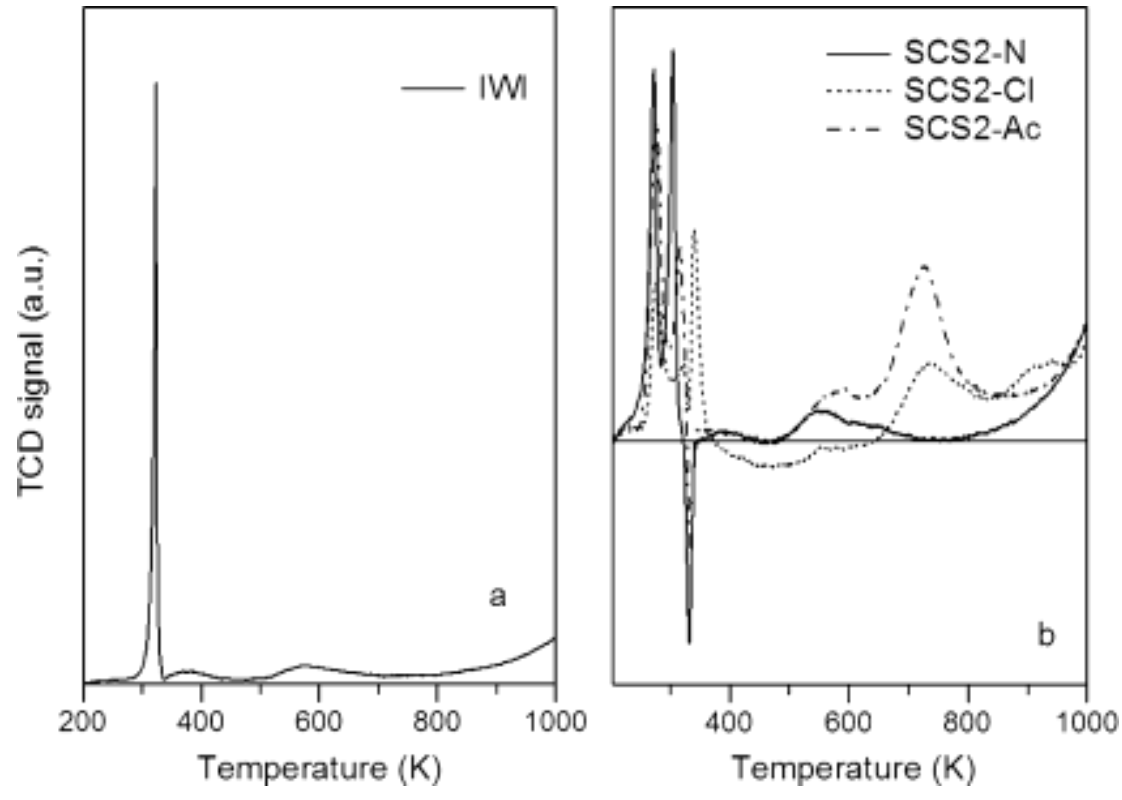

Figure 6. TPR profiles of a) IWI and b) SCS samples.

are reduced more easily than IWI. This evidence matches well with the XPS results, which indicate that IWI is the most oxidized catalyst. MT peaks are more pronounced and cover a broader temperature range for SCS2-Ac and SCS2-CI, whereas for SCS2-N they are similar to those of IWI. In the HT region, all the samples show a similar trend for hydrogen uptake.

SCS2-N and SCS2-Ac show a similar behavior, with the presence of two hydrogen-consumption peaks followed by a hydrogen-release peak caused by the decomposition of b-type palladium hydrides. ${ }^{[19]}$ In the case of SCS2-Cl, the peak caused by hydrogen release appears in the middle of the two hydrogenuptake features and its evolution is clearly stopped by the appearance of the second peak. The general identification of every peak of the LT region is not straightforward. According to Luo and Zheng, ${ }^{[21]}$ the splitting of the hydrogen-consumption peak at low temperature over a $\mathrm{PdO} / \mathrm{Ce}_{0.5} \mathrm{Zr}_{0.5} \mathrm{O}_{2}$ catalyst is related to the conditions of $\mathrm{Pd}$ oxidation and can be caused by the nonuniform size distribution of $\mathrm{PdO}$ and/or to the inclusion of some $\mathrm{PdO}$ into the support after redox cycles. In this case, the inclusion of $\mathrm{PdO}$ in the ceria lattice is observed for all SCS samples; moreover, the particular characteristics of SCS (fast evolution, exothermicity, different local temperatures during combustion) might give rise to nonuniform $\mathrm{Pd}$ particle size and different Pd oxidation states. From XPS analysis, it is observed that the predominant phase on these catalysts is a nonstoichiometric palladium oxide that is likely to react with hydrogen in a more complex way than bulk $\mathrm{PdO}$, which predominates on IWI. It is also known that noble metals develop strong interactions on ceria under reducing conditions that can result, for example, in the decoration of $\mathrm{Pd}$ particles by

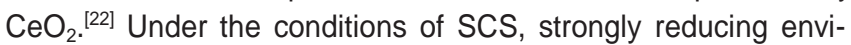
ronments might be established locally during reaction leading to the formation of such decorated particles and/or to other types of $\mathrm{Pd}$-Ce alloys ${ }^{[23]}$ beside the ordered supercell structure observed on SCS2-N.
From the quantitative analysis reported in Table 4, it appears that there is an amount of hydrogen spillover onto the support for SCS2-Ac as the theoretical percentage of $\mathrm{PdO}$ reduction exceeds $100 \%$. The same is true for IWI because the recorded hydrogen consumption is $\partial 60 \%$ higher than the stoichiometric amount calculated for $\mathrm{PdO}$ reduction. For SCS2-N and SCS2$\mathrm{Cl}$, a degree of reduction close (SCS2-Cl) or slightly above unity (SCS2-N) likely includes a reduction of the ceria support as these samples present a certain amount of metallic $\mathrm{Pd}$ (seen from XRD, XPS, and HRTEM results). The spillover of $\mathrm{H}_{2}$ onto a reducible support in the presence of a noble metal is a wellknown phenomenon. ${ }^{[24]}$

\begin{tabular}{|c|c|c|c|c|}
\hline Sample & $\begin{array}{l}\mathrm{H}_{2} \text { uptake } \\
{[\mathrm{mL}]}\end{array}$ & $\begin{array}{l}\mathrm{H}_{2} \text { release } \\
{[\mathrm{mL}]}\end{array}$ & $\begin{array}{l}\mathrm{PdO} \text { red } \\
{[\%]^{[a]}}\end{array}$ & $\begin{array}{l}\mathrm{PdH} \text { dec } \\
{[\%]^{[b]}}\end{array}$ \\
\hline IWI & 0.39 & - & 164 & - \\
\hline SCS2-N & 0.28 & 0.06 & 107 & 22 \\
\hline SCS2-Cl & 0.23 & - & 90 & - \\
\hline SCS2-AC & 0.27 & 0.02 & 142 & 10 \\
\hline
\end{tabular}

[a] $\%$ of $\mathrm{PdO}$ reduced during TPR, calculated on the basis of the actual $\mathrm{Pd}$ loading. [b] \% of PdH decomposed during TPR, calculated on the basis of the actual Pd loading.

The hydrogen consumption in the MT region is very small for IWI and SCS2-N and approximately three to four times higher for SCS2-Cl and SCS2-Ac, respectively. This hydrogen uptake is smaller than that observed on pure $\mathrm{CeO}_{2}$ prepared by SCS (Supporting Information). This is consistent with the spillover observed in the LT region: in the presence of the noble metal, ceria tends to be reduced at a lower temperature. The differences between the samples prepared from different precursors are difficult to explain in the MT region, but these might be related to the different evolution of carbon-containing species that are still present on the catalyst surface.

TPO experiments add some other details to the redox properties of the catalysts. The oxygen-release and -uptake profiles of SCS samples during the third TPO cycle are shown in Figure 7. The third cycle is chosen as representative as no further modification of TPO profiles can be detected from this cycle onwards; moreover, this cycle is somehow representative of the state of the catalysts during the combustion cycles. From the cooling part of the cycles, it can be observed that the temperature and the dynamics of $\mathrm{Pd}$ reoxidation are simi- 


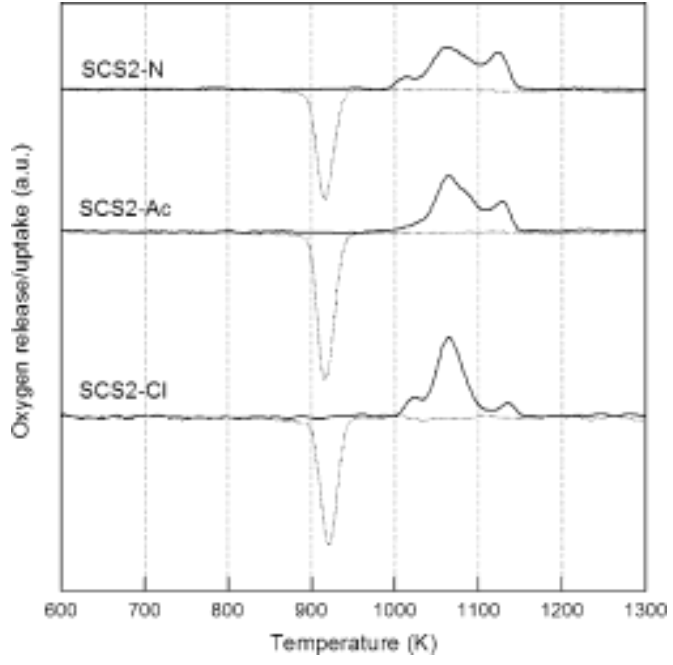

Figure 7. TPO profiles of the third cycle for all SCS samples (solid line: heating; dotted line: cooling).

lar for all catalysts, exhibiting a single peak with a minimum at ð $920 \mathrm{~K}$. A different picture appears if we look at the oxygenrelease profile (heating ramp): in this case a clear difference is observed between SCS2-N and SCS2-Ac on one side and SCS2$\mathrm{Cl}$ on the other. $\mathrm{PdO}$ decomposition takes place mostly below $1073 \mathrm{~K}$ on SCS2-Cl, whereas a significant part of PdO is decomposed above $1073 \mathrm{~K}$ for SCS2-N and SCS2-Ac. For alumina-supported $\mathrm{Pd}$, the fraction of $\mathrm{PdO}$ that decomposes at a higher temperature has been attributed tentatively to surface $\mathrm{PdO}$, to $\mathrm{PdO}$ that interacts strongly with the support, ${ }^{[17]}$ and to the decomposition of a core of $\mathrm{PdO}$ covered by a shell of $\mathrm{Pd}$ metal. ${ }^{[25]}$ On these Pd-ceria systems, we can hypothesize a similar scenario in which the occurrence of separate steps during $\mathrm{PdO}$ decomposition might correspond to different $\mathrm{PdO}$ species or to $\mathrm{PdO}$ in different environments (bound more strongly to the support, covered by Pd metal etc.). In general, these steps are more evident on the SCS samples than on the IWI sample (Figure S3) in agreement with the results from TPR and with XPS analysis, which shows the predominance of $\mathrm{PdO}_{x}$ on the SCS catalysts.

Quantitative analysis performed during TPO indicates clearly that a higher amount of $\mathrm{Pd}$ undergoes oxidation-decomposition on SCS2-Ac (Table 5). The amount of Pd cycling is in the order SCS2-Ac $>|W|>$ SCS2-CI SCS2-N.

The results of reaction rate measurements during methane combustion performed in the recycle reactor are reported in Table 6. The use of the recycle reactor ensures the differential

\begin{tabular}{l}
\hline Table 5. Quantitative analysis for TPO experiments . \\
\begin{tabular}{|lllll|}
\hline Sample & $\begin{array}{l}\text { Oxygen release } \\
{\left[\times 10^{-3} \mathrm{mmol}_{\left.\mathrm{Pd}^{-1}\right]}\right]}\end{array}$ & $\begin{array}{l}\text { Oxygen uptake } \\
{\left[\times 10^{-3} \mathrm{mmol}_{\mathrm{Pd}}{ }^{-1}\right]}\end{array}$ & $\begin{array}{l}\mathrm{PdO} \text { decomposition } \\
{[\%]}\end{array}$ & $\begin{array}{l}\mathrm{Pd} \text { oxidation } \\
{[\%]}\end{array}$ \\
\hline IWI & 3.76 & 3.79 & 80 & 81 \\
SCS2-N & 3.34 & 3.28 & 71 & 69 \\
SCS2-Cl & 3.42 & 3.40 & 73 & 72 \\
SCS2-Ac & 4.06 & 4.29 & 86 & 91 \\
\hline
\end{tabular}
\end{tabular}

Table 6. Reaction rates for all samples calculated at $573 \mathrm{~K}$.
\begin{tabular}{|lcc|}
\hline Sample & \multicolumn{2}{c|}{ Reaction rates } \\
& ${\text { mmolg } \mathrm{Pd}^{-1} \mathrm{~s}^{-1}}$ & $\times 10^{2} \mathrm{mmol} \mathrm{m}^{-2} \mathrm{~s}^{-1}$ \\
\hline IWI & 10.0 & 1.4 \\
SCS2-N & 23.6 & 6.9 \\
SCS2-Cl & 23.4 & 7.6 \\
SCS2-Ac & 25.2 & 4.0 \\
2PdIW_CeSCS & 9.7 & 1.3 \\
2Pd/Al $\mathrm{O}_{3}$ & 23.9 & 0.5 \\
\hline
\end{tabular}

conditions necessary to obtain consistent rate values. Moreover, the measurement of the rate during the second catalytic cycle avoids the problems related to sintering and redispersion of $\mathrm{Pd}$ particles during the reaction ${ }^{[26]}$ and ensures stable catalytic behavior because the third cycle is almost identical to the second one. The reaction rates measured for SCS samples based on noble metal loading are more than twice the rates measured on IWI. The difference is even higher if we compare the results based on the surface area as the surface area of the SCS samples is much lower than that of IWI. This effect is already known for SCS2-N for the combustion of methane, ${ }^{[12]}$ propane, and dimethyl ether. ${ }^{[14]}$ To evaluate whether this effect could be related to a particular structure of the ceria support made by SCS that can interact differently with $\mathrm{Pd}$, a sample that consisted of $\mathrm{Pd}$ impregnated on $\mathrm{CeO}_{2}$ made by SCS has been prepared and tested. This catalyst, 2PdIW_CeSCS, showed a reaction rate very close to that of IWI, which thus excludes an effect of the SCS ceria support in the enhancement of the catalytic performance. In addition, we measured the reaction rate on a 2 wt $\% \mathrm{Pd} / \mathrm{Al}_{2} \mathrm{O}_{3}$ catalyst prepared by incipient wetness impregnation with a similar procedure to that reported for the IWI sample. The results indicate that, although the surface area is much higher than that of the SCS samples $\left(93.5 \mathrm{~m}^{2} \mathrm{~g}^{-1}\right)$, the reaction rate at $573 \mathrm{~K}$ is similar. As widely known from the literature, ${ }^{[27]}$ the alumina-based catalyst shows a much higher deactivation during the cooling branch of the light-off curve (Figure S7) with respect to ceria-based materials, which makes the ceria-based materials very interesting from the point of view of practical applications.

The values of the reaction rates measured on SCS samples indicate that there is no significant effect of the different $\mathrm{Po}$ precursors on catalytic activity, although it is clear that the synthesis route plays a major role. XPS analysis of fresh samples evidences a higher degree of oxidation for IWI than the SCS catalysts; even so this difference almost disappears after one methane combustion cycle as revealed by XPS of the spent catalysts. These evidences tend to exclude that different $\mathrm{Pd}$ oxidation states are responsible for the higher reaction rates recorded on all SCS samples. However, the presence of the ordered Pd-O-Ce superstructure on SCS2-N after reaction detected by HRTEM supports the role of this structure, and that of its nonordered counterpart, in the higher methane combustion activity. On the basis of these results, it is reasonable to conclude that the presence of highly dispersed $\mathrm{Pd}^{2+}$ ions in the ceria lattice, or- 
dered or not, is key to achieve superior methane combustion activity. This explanation is in agreement with the work of Cargnello et al. in which a very high activity for methane combustion on $\mathrm{Pd} /$ ceria catalyst was recorded, which was related to the presence of undercoordinated $\mathrm{Pd}$ atoms in close interaction with $\mathrm{CeO}_{2} \cdot{ }^{\left[{ }^{[28]}\right.}$ Priolkar and co-workers attributed the higher activity observed for $\mathrm{CO}$ oxidation and $\mathrm{NO}$ reduction to the formation of a Pd-O-Ce solid solution. ${ }^{[16]}$ Moreover, the theoretical work performed by Mayernick and Janik indicates that the presence of substitutional $\mathrm{Pd}$ ions in the ceria lattice lowers not only the energy barrier for the formation of oxygen vacancies but also the reaction energy for methane adsorption, that is, the first step for catalytic combustion. ${ }^{[13]}$

\section{Conclusions}

We characterized different Pd-ceria catalysts prepared by solution combustion synthesis (SCS) starting from different Pd precursors and tested for methane catalytic combustion. Characterization results indicate the presence on all SCS samples of a Pd-Ce solid solution, which appears as an ordered supercell structure on SCS2-N. The occurrence of this ordered structure has been related tentatively to the enthalpy of reaction $\mathrm{DH}_{\text {react }}$ between palladium nitrate and the fuel (oxalyl dihydrazide) during SCS. The value of $\mathrm{DH}_{\text {react }}$ for $\mathrm{Pd}\left(\mathrm{NO}_{3}\right)_{2}$ is much more exothermic than that for $\mathrm{Pd}\left(\mathrm{O}_{2} \mathrm{CCH}_{3}\right)_{2}$ and $\mathrm{PdCl}_{2}$ (slightly endothermic). The results obtained in this study explain the higher catalytic activity for methane combustion recorded on all SCS samples in relation to their peculiar structure: on one side this particular $\mathrm{Pd}$-ceria interaction is evident from structural and morphological characterization (X-ray photoelectron spectroscopy, XRD, high-resolution TEM), on the other it is underlined by the redox behavior of these samples (temperature-programmed reduction and oxidation), which is clearly different and more complex with respect to that of the impregnated counterpart, regardless of the Pd precursor. It seems then plausible to ascribe the superior activity for methane combustion recorded on SCS samples to the substitution of $\mathrm{Pd}^{2+}$ ions into the ceria lattice, which is random for SCS2-Cl and SCS2-Ac and ordered for SCS2-N. Our results indicate that these catalytic systems show promise in the field of methane abatement for the control of greenhouse gas emissions in light of their comparison with state-of-the-art $\mathrm{Pd}$-alumina catalysts.

\section{Experimental Section}

A series of $2 \mathrm{wt} \% \mathrm{Pd} / \mathrm{CeO}_{2}$ catalysts was prepared by SCS. In this technique $\mathrm{Pd}$ and $\mathrm{Ce}$ precursor salts are mixed in a suitable amount of water to which a reducer, or fuel, is added. In this work, $\left(\mathrm{NH}_{4}\right)_{2} \mathrm{Ce}\left(\mathrm{NO}_{3}\right)_{6}$ (ceric ammonium nitrate, $\mathrm{CAN}$ ) was used as the $\mathrm{CeO}_{2}$ precursor, and $\mathrm{Pd}\left(\mathrm{NO}_{3}\right)_{2}, \mathrm{PdCl}_{2}$, and $\mathrm{Pd}\left(\mathrm{O}_{2} \mathrm{CCH}_{3}\right)_{2}$ were used as $\mathrm{Pd}$ precursors. The fuel was $\mathrm{ODH}\left(\mathrm{C}_{2} \mathrm{H}_{6} \mathrm{~N}_{4} \mathrm{O}_{2}\right)$. Fuel and precursors in a stoichiometric amount were dissolved in water and placed in a preheated furnace (Tð623 K) for the combustion to take place. After complete combustion, the samples were removed from the furnace and cooled to RT. The overall theoretical combustion reactions are shown in Equations (2)-(4):
0:03PdðNO ${ }_{3} \mathrm{P}_{2}$ p0:97CANp2:358ODH ! 0:03PdOp0:97 $\mathrm{CeO}_{2}$ p4:716 $\mathrm{CO}_{2}$ p10:954 $\mathrm{H}_{2} \mathrm{Op} 8: 626 \mathrm{~N}_{2}$

0:03 $\mathrm{PdCl}_{2}$ p0:97CANp2:328ODH ! 0:03 PdOp0:97 $\mathrm{CeO}_{2}$ p4:641 $\mathrm{CO}_{2}$ p10:864 $\mathrm{H}_{2} \mathrm{Op} 8: 536 \mathrm{~N}_{2} \mathrm{po:03} \mathrm{Cl}_{2} \mathrm{p0}: 135 \mathrm{C}$

0:03 PdðO ${ }_{2} \mathrm{CCH}_{3} \mathrm{P}_{2}$ p0:97 CANp2:328 ODH ! 0:03 PdOp0:97 $\mathrm{CeO}_{2}$ p4:656 $\mathrm{CO}_{2}$ p10:954 $\mathrm{H}_{2} \mathrm{Op} 8: 536 \mathrm{~N}_{2} \mathrm{po:12} \mathrm{C}$

The amount of fuel for each reaction was calculated to balance the net oxidizing valence of the salts involved by considering only nitrate compounds as the oxidizer. ${ }^{[2]}$ The IWI catalyst that consisted of $2 \mathrm{wt} \% \mathrm{Pd}$ on commercial $\mathrm{CeO}_{2}$ (Grace Davison) was prepared by traditional incipient wetness impregnation for comparison with SCS samples from a solution of 10 wt \% $\mathrm{Pd}\left(\mathrm{NO}_{3}\right)_{2}$ (Aldrich, $99.999 \%$ ). The impregnated sample was dried overnight at $393 \mathrm{~K}$ and then calcined at $1173 \mathrm{~K}$ in a furnace with circulating air for $4 \mathrm{~h}$. Characterization methods are reported in the Supporting Information. Catalytic tests and reaction rate measurements were performed in a recycle reactor ${ }^{[14]}$ with a total flow rate of $40 \mathrm{~mL} \mathrm{~min}{ }^{-1}$ and a recycle ratio of 35 . The feed gas composition was $0.5 \% \mathrm{CH}_{4}$ and $2 \% \mathrm{O}_{2}$ in $\mathrm{He}$. The sample (100 mg, pressed and sieved) was loaded into a quartz microreactor (i.d. $4 \mathrm{~mm}$, length $400 \mathrm{~mm}$ ) on a quartz wool bed, and the temperature was monitored by using a thermocouple positioned in the catalyst bed. The effluent gases were monitored by using an Omnistar Quadrupole Mass Spectrometer and a Varian CP 4900 micro gas chromatograph equipped with molecular sieve and Poraplot $Q$ columns. For reaction rate measurements, a first heating/cooling cycle was performed up to $1173 \mathrm{~K}$, during which the light-off curves of methane combustion were recorded (Supporting Information), then the temperature was increased to $573 \mathrm{~K}$ at a heating rate of $10 \mathrm{~K} \mathrm{~min}^{-1}$. The rate was calculated using the conversion value measured after $2 \mathrm{~h}$ of holding time at $573 \mathrm{~K}$; during this period no significant variation in conversion values was observed.

\section{Acknowledgements}

We thank regione FVG for support. J.L. is a Serra Hfflnter Fellow and is grateful to the ICREA Academia program and MINECO grant ENE2012-36368.

Keywords: cerium - heterogeneous catalysis - hydrocarbons . palladium · reduction

[1] a) S. T. Aruna, A. S. Mukasyan, Curr. Opin. Solid State Mater. Sci. 2008, 12, 44-50; b) S. L. Gonzffllez-Cortfs, F. E. Imbert, Appl. Catal. A 2013, 452, $117-131$.

[2] K. Suresh, K. C. Patil in Perspectives in Solid State Chemistry (Ed.: K. J. Rao), Narosa Publishing House, New Delhi, 1995, pp. 376-388.

[3] a) S. Sharma, M. S. Hegde, R. N. Das, M. Pandey, Appl. Catal. A 2008, 337, 130-137; b) A. Vita, G. Cristiano, C. Italiano, S. Specchia, F. Cipiti, V. Specchia, Int. j. Hydrogen Energy 2014, 39, 18592-18603.

[4] a) P. Dinka, A. Mukasyan, WO2007019332A1, 2007; b) Q. Weng, D. Sun, S. Lin, J. Chen, S. Xie, R. Huang, L. Zheng, CN101503188 (A), 2009.

[5] P. Bera, K. C. Patil, M. S. Hegde, Phys. Chem. Chem. Phys. 2000, 2, 37153719 .

[6] a) B. T. Zhao, X. Yu, R. Cai, R. Ran, H. T. Wang, Z. P. Shao, J. Mater. Chem. 2012, 22, 2900-2907; b) X. Li, Q. Xiao, B. Liu, H. C. Lin, J. B. Zhao, J. Power Sources 2015, 273, 128-135. 
[7] a) E. Thomas, D. H. Lee, M. Y. Yoon, S. H. Ehrman, H. J. Hwang, Ceram. Int. 2011, 37, 2269-2274; b) C. Y. Zhu, A. Nobuta, Y. W. Ju, T. Ishihara, T. Akiyama, Int. J. Hydrogen Energy 2013, 38, 13419-13426.

[8] a) A. Kumar, A. S. Mukasyan, E. E. Wolf, Appl. Catal. A 2011, 401, 20-28; b) A. Vita, G. Cristiano, C. Italiano, L. Pino, S. Specchia, Appl. Catal. B 2015, 162, 551-563

[9] a) G. Ramakrishna, H. Nagabhushana, D. V. Sunitha, S. C. Prashantha, S. C. Sharma, B. M. Nagabhushana, Spectrochim. Acta Part A 2014, 127, 177-184; b) Y. S. Vidya, K. S. Anantharaju, H. Nagabhushana, S. C. Sharma, H. P. Nagaswarupa, S. C. Prashantha, C. Shivakumara, Danithkumar, Spectrochim. Acta Part A 2015, 135, 241-251.

[10] a) S. K. Ghosh, A. Prakash, S. Datta, S. K. Roy, D. Basu, Bull. Mater. Sci. 2010, 33, 7-16; b) M. A. Aghayan, M. A. Rodriguez, Mater. Sci. Eng. C 2012, 32, 2464-2468.

[11] a) S. Specchia, E. Finocchio, G. Busca, P. Palmisano, V. Specchia, J. Catal. 2009, 263, 134-145; b) V. M. Shinde, G. Madras, Catal. Today 2012, 198 270-279; c) R. Mistri, M. Rahaman, J. Llorca, K. R. Priolkar, S. Colussi, B. C. Ray, A. Gayen, J. Mol. Catal. A 2014, 390, 187-197; d) M. Piumetti, D. Fino, N. Russo, Appl. Catal. B 2015, 163, 277-287.

[12] S. Colussi, A. Gayen, M. F. Camellone, M. Boaro, J. Llorca, S. Fabris, A Trovarelli, Angew. Chem. Int. Ed. 2009, 48, 8481-8484; Ángew. Chem. 2009, 121, 8633-8636.

[13] a) A. D. Mayernick, M. J. Janik, J. Phys. Chem. C 2008, 112, 14955-14964; b) A. D. Mayernick, M. J. Janik, J. Catal. 2011, 278, 16-25.

[14] S. Colussi, A. Gayen, J. Llorca, C. de Leitenburg, G. Dolcetti, A. Trovarelli, Ind. Eng. Chem. Res. 2012, 51, 7510-7517.

[15] a) H. Nasiri, E. B. Motlagh, J. V. Khaki, S. M. Zebarjad, Mater. Res. Bull. 2012, 47, 3676-3680; b) A. B. Salunkhe, V. M. Khot, M. R. Phadatare, S. H. Pawar, J. Alloys Compd. 2012, 514, 91-96; c) S. Hajarpour, K. Gheisari, A. H. Raouf, J. Magn. Magn. Mater. 2013, 329, 165-169; d) R. lanos, R. Babuta, R. Lazau, Ceram. Int. 2014, 40, 12207-12211.
[16] K. R. Priolkar, P. Bera, P. R. Sarode, M. S. Hegde, S. Emura, R. Kumashiro, N. P. Lalla, Chem. Mater. 2002, 14, 2120-2128.

[17] S. Colussi, A. Trovarelli, E. Vesselli, A. Baraldi, G. Comelli, G. Groppi, J. Llorca, Appl. Catal. A 2010, 390, 1-10.

[18] a) Y. R. Wu, W. Y. Hu, S. C. Han, J. Alloys Compd. 2006, 420, 83-93 b) V. L. Vinograd, M. H. F. Sluiter, B. Winkler, Phys. Rev, B 2009, 79 104201.

[19] a) G. Chen, W.-T. Chou, C. T. Yeh, Appl. Catal. 1983, 8, 389-397; b) T. C Chang, J.J. Chen, C. T. Yeh, J. Catal. 1985, 96, 51-57; c) H. Lieske, J. Volter, J. Phys. Chem. 1985, 89, 1841-1842.

[20] A. Trovarelli, Catal. Rev. 1996, 38, 439-520.

[21] M. F. Luo, X. M. Zheng, Appl. Catal. A 1999, 189, 15-21.

[22] S. Bernal, J. J. Calvino, M. A. Cauqui, J. M. Gatica, C. Larese, J. A. P. Omil J. M. Pintado, Catal. Today 1999, 50, 175-206.

[23] L. Kepiński, M. Wolcyrz, J. Okal, J. Chem. Soc. Faraday Trans. 1995, 91 , 507-515.

[24] W. C. Conner, J. L. Falconer, Chem. Rev. 1995, 95, 759-788.

[25] X. Y. Chen, J. W. Schwank, G. B. Fisher, Y. S. Cheng, M. Jagner, R. W. McCabe, M. B. Katz, G. W. Graham, X. Q. Pan, Appl. Catal. A 2014, 475 $420-426$.

[26] O. Demoulin, G. Rupprechter, I. Seunier, B. Le Clef, M. Navez, P. Ruiz, J. Phys. Chem. B 2005, 109, 20454-20462.

[27] a) R. J. Farrauto, M. C. Hobson, T. Kennelly, E. M. Waterman, Appl. Catal. A 1992, 81, 227-237; b) J. G. McCarty, Catal. Today 1995, 26, 283-293.

[28] M. Cargnello, J. J. D. Jaen, J. C. H. Garrido, K. Bakhmutsky, T. Montini, J. J. C. Gamez, R. J. Gorte, P. Fornasiero, Science 2012, 337, 713-717. 